\title{
Chlordiazepoxide and the determinants of negative contrast
}

\author{
CHARLES F. FLAHERTY, PATRICIA S. GRIGSON, and GRACE A. ROWAN \\ Rutgers University, New Brunswick, New Jersey
}

\begin{abstract}
Previous experiments have shown that the negative contrast effect in consummatory behavior that occurs when rats are shifted from $32 \%$ to $4 \%$ sucrose is alleviated by the tranquilizer chlordiazepoxide (CDP). However, in these experiments, CDP was effective on the second postshift day but not on the first postshift day. The three experiments described in this paper suggest that this differential effectiveness of CDP is not due to the difference in preshift-postshift retention intervals on Day $1(24 \mathrm{~h})$ and Day $2(48 \mathrm{~h})$, but is due instead to the necessity of some degree of experience (about $5 \mathrm{~min}$ ) with the postshift solution. These results, combined with those of an earlier study which showed elevated corticosterone in shifted animals on the second postshift day but not on the first postshift day, suggest that negative contrast may be a dynamic process, involving sequential processes of detection, evaluation, and conflict over the postshift period. It was further suggested that CDP becomes effective in moderating contrast only when the conflict stage is reached.
\end{abstract}

Rats shifted from a $32 \%$ to a $4 \%$ sucrose solution consume substantially less of the $4 \%$ sucrose than do rats that have experienced only the $4 \%$ solution. This negative contrast effect that follows the shift in sucrose solutions is usually largest on the first postshift day and then declines so that, typically, by the fourth or fifth postshift day the shifted and unshifted animals are consuming approximately the same amount of $4 \%$ sucrose (e.g., Flaherty \& Lombardi, 1977; Flaherty, Lombardi, Wrightson, \& Deptula, 1980; Lombardi \& Flaherty, 1978).

A frequent interpretation of negative contrast that occurs in runway behavior is that the reward downshift elicits an emotional response, such as frustration, which competes with approaching the goal area. This competition results in slower running, which is measured as negative contrast (Amsel \& Stanton, 1980; Crespi, 1944; Flaherty, 1982; Spence, 1956; Stanton, Lobough, \& Amsel, 1984). One approach to investigating the possible role of emotional factors in contrast is to examine the effects of various drugs that are thought to influence emotional behavior. Thus, it has been found that negative contrast in runway behavior may be eliminated by the tranquilizer chlordiazepoxide (CDP) and the barbiturate sodium amobarbital, but it is not influenced by the neuroleptic chlorpromazine (Roberts \& Pixley, 1965; Rosen, Glass, \& Ison, 1967; Rosen \& Tessel, 1970).

We have also found differential effects with a number of drugs in the consummatory negative contrast situation.

This research was supported by Grant No. MH-40489-01 from the National Institutes of Mental Health and by a grant from the Charies and Johanna Busch bequest. The assistance of Mary Osborne in Experiment $2 a$ and Ann Brady in Experiment $2 b$ is appreciated. Address correspondence to Charles Flaherty, Psychology Department, Busch Campus, Rutgers University, New Brunswick, NJ 08903.
Thus, to a greater or lesser degree, the anxiolytic agents CDP, midazolam, sodium amobarbital, ethanol, and morphine tend to reduce contrast (Becker, 1986; Becker \& Flaherty, 1982, 1983; Flaherty, Becker, \& Driscoll, 1982; Flaherty \& Driscoll, 1980; Flaherty, Lombardi, Wrightson, \& Deptula, 1980; Rowan \& Flaherty, 1986). Nonanxiolytics, such as scopolamine, methysergide, pyrilamine, propranolol, and haloperidol, do not reduce contrast (Becker, 1986; Flaherty \& Meinrath, 1979; Flaherty \& Rowan, unpublished data).

However, we have also found an unexpected pattern in these results. Some of these drugs, CDP and ethanol in particular, are substantially more effective when administered for the first time on the second postshift day. Indeed, these drugs are typically without effect when administered on the first postshift day (Becker \& Flaherty, 1982; Flaherty et al., 1980). A similar pattern was found when a novel tone was used as a disinhibitory stimulus. That is, contrast was reduced by presentation of the novel tone, but only on the second and subsequent postshift days (Lombardi \& Flaherty, 1978).

What could account for the differential effectiveness of these drugs across the postshift period? One possibility is that the emotional response on the first postshift day is greater than that on the second postshift day-great enough to render the administered drug ineffective. However, a recently completed experiment showed that there was a substantial corticosterone elevation correlated with contrast on the second postshift day, but no elevation in corticosterone at all on the first postshift day (Flaherty, Becker, \& Pohorecky, 1985). These data suggest that the second postshift day is more stressful than the first postshift day. The present paper is concerned with the further investigation of the differential effectiveness of CDP across the first and second postshift days. 


\section{EXPERIMENT 1}

In order to show a contrast effect, the shifted animals must be able to compare the postshift reward with the memory of the preshift reward (Spear, 1967). As the interval between the preshift period and any given postshift day increases, the memory of the preshift reward should become more tenuous and, therefore, the comparison process that must underlie contrast more problematical. It is not surprising, then, that degree of contrast diminishes as the interval between the last preshift day and the first postshift day increases. This result has been obtained in runway studies (e.g., Gonzalez, Fernhoff, \& David, 1973), as well as in the consummatory contrast procedure (e.g., Ciszewski \& Flaherty, 1977; Flaherty \& Lombardi, 1977). It has also been shown that the insertion of a retention interval between the first and second postshift day will lead to a reduction in degree of contrast on the second postshift day (Gleitman \& Steinman, 1964).

The present experiment is concerned with the possibility that the marked effectiveness of CDP in reducing contrast on the second postshift day, compared to its lack of effect on the first postshift day, is related to a memory function. That is, the second postshift day occurs $48 \mathrm{~h}$ after the animals' last experience with the preshift solution, whereas the first postshift day follows the last preshift day by only $24 \mathrm{~h}$. It is possible that this difference is sufficient to weaken the comparison between preshift and postshift rewards enough to allow the drug, and the previously mentioned disinhibitory stimulus, to be effective on the second postshift day.

In order to examine this possibility, we delayed the first postshift day until $48 \mathrm{~h}$ after the last preshift day. The effectiveness of CDP in reducing contrast was examined in a group of animals with a "normal" first postshift day (24 $\mathrm{h}$ after the last preshift day) and in a group with the delayed $(48 \mathrm{~h})$ first postshift day. If memory processes are responsible for the Day 1-Day 2 differences in drug effectiveness seen in the earlier studies, then CDP should be effective in reducing contrast in the 48 -h group but not in the 24-h group.

\section{Method}

Subjects. Forty-eight male 90-day-old Sprague-Dawley-derived rats purchased from Blue Spruce Farms were used as subjects. The rats were maintained at $82 \%$ of their free-feeding weights by onceper-day feeding. They were housed individually and maintained on a $14 \mathrm{~h} / 10 \mathrm{~h}$ light/dark cycle. Daily sessions occurred approximately $2 \mathrm{~h}$ into the light phase of the cycle.

Apparatus. Testing was conducted in six identical metal grid cages $(24.5 \times 17.5 \times 18 \mathrm{~cm})$. A centrally located hole $(1 \mathrm{~cm}$ in diameter) $7 \mathrm{~mm}$ above the floor was present in one wall of each cage. A graduated cylinder was placed outside of each chamber so that the orifice of the drinking spout was centered in the hole and flush with one wall of the chamber. Licking was recorded through a contact relay circuit by microprocessors.

Procedure. During the preshift phase of the experiment (10 days), half of the subjects were given daily access ( $5 \mathrm{~min}$ per day) to a $32 \%$ sucrose solution and half were given daily access to a $4 \%$ su- crose solution. During the postshift period (4 days), the $32 \%$ group was shifted to $4 \%$ sucrose, whereas the $4 \%$ group was maintained on the $4 \%$ solution.

For half of the animals in each group (shifted and unshifted), the first postshift day occurred $24 \mathrm{~h}$ after the last preshift day. For the remaining animals, the first postshift day occurred $48 \mathrm{~h}$ after the last preshift day. The latter animals were weighed and fed normally on the day that was omitted from their running schedule.

On the first postshift day, half of the animals in each group defined by the factorial combination of shift condition (shifted and unshifted) and retention interval ( $24 \mathrm{~h}$ and $48 \mathrm{~h}$ ) were injected with CDP $(8 \mathrm{mg} / \mathrm{kg})$ and half were injected with isotonic saline. The injections were administered ip $30 \mathrm{~min}$ prior to the start of the first postshift session. The CDP was donated by Hoffman-LaRoche, Nutley, New Jersey. The sucrose solutions were prepared by weight (sucrose/[sucrose + water]) from commercial-grade cane sugar and tap water $24 \mathrm{~h}$ before each session.

\section{Results}

Over the terminal preshift period (Days 9-10), the animals given $32 \%$ sucrose licked more (mean $=1,393.9$ ) than did the animals given $4 \%$ sucrose (mean $=1,237.9$ ), a difference that was statistically reliable $[F(1,30)=4.81$, $p<.05$ ]

The rats shifted from $32 \%$ to $4 \%$ sucrose showed a drop in lick frequency to a level substantially below that of the unshifted animals (Figure 1). This negative contrast effect was highly reliable $[F(1,29)=34.71, p<.001]$ and tended to recover across days $[F(3,86)=16.37$, $p<.001]$. The effect of CDP on contrast is more clearly seen in Figure 2, which illustrates the data from the first postshift day (the one day on which the drug was injected). The contrast effect (shifted < unshifted) on this day was large and reliable $[F(1,28)=78.63, p<.001]$. The injection of CDP had the effect of increasing lick frequency in all groups $[F(1,28)=7.57, p<.02]$. However, the drug did not differentially increase the lick frequency of the shifted animals relative to that of the unshifted animals $(F<1.00)$, and, most importantly, it did not have a differential effect as a function of whether the first postshift day was $24 \mathrm{~h}$ or $48 \mathrm{~h}$ after the last preshift day (drug $x$ interval and shift $\times$ drug $\times$ interval $F$ s $<1$ ). Thus, CDP did not reduce contrast.

\section{Discussion}

Previous studies have shown that CDP has a substantial contrast-reducing effect when administered for the first time on the second postshift day, but no effect on contrast when administered on the first postshift day (Flaherty et al., 1980). The present experiment shows that the differential effectiveness of the drug on the second postshift day is not due to the passage of a $48-\mathrm{h}$ interval between the last preshift day and the second postshift day. That is, when a 48-h interval was allowed to elapse between the last preshift day and the first postshift day, the drug did not reduce contrast. It is important to note that CDP did have one effect in this study: it increased overall lick frequency, a reflection of the often-reported appetite-stimulating properties of the benzodiazepines 


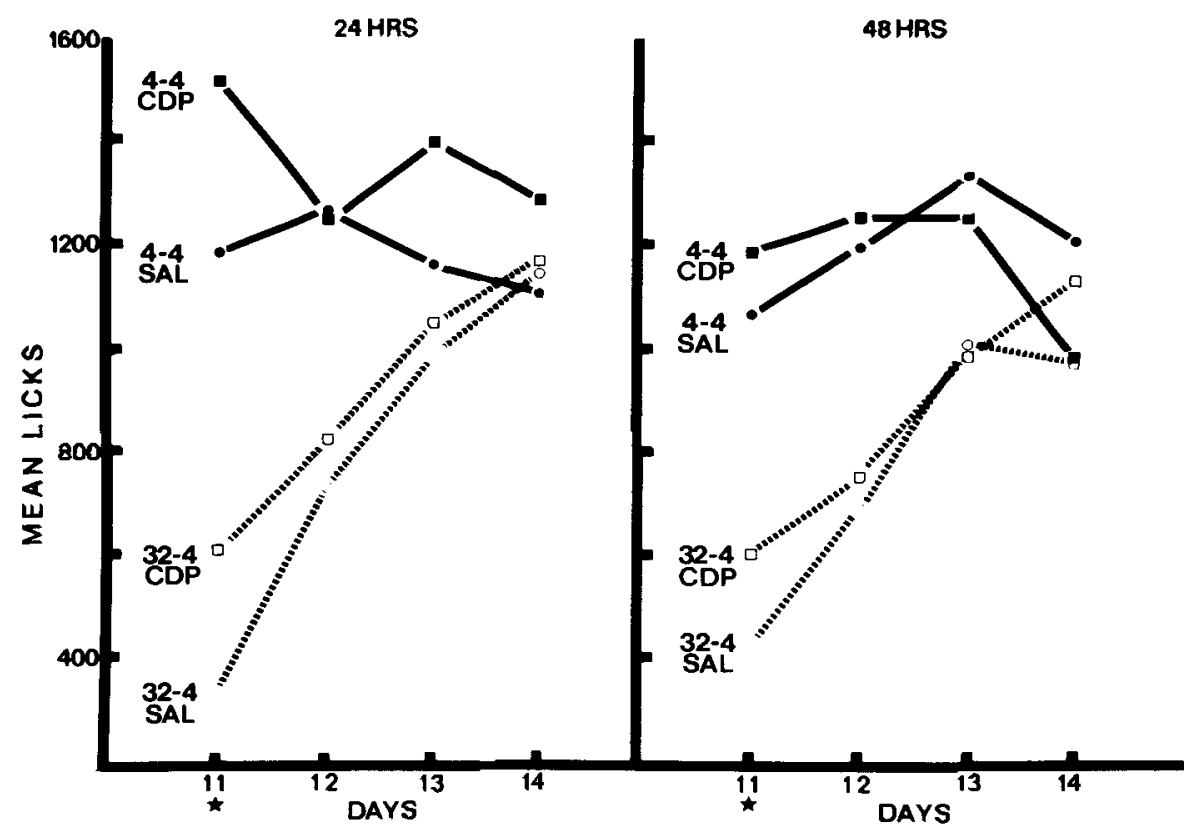

Figure 1. Mean lick frequency across 4 postshift days. Shifted animals (dotted lines) showed contrast effects which diminished across the postshift period. Degree of contrast was equivalent in 24-h and 48-h first-postshift-day groups. Chlordiazepoxide (CDP) did not reduce contrast in either group when it was injected on the first postshift day (Day 11).

24 HRS

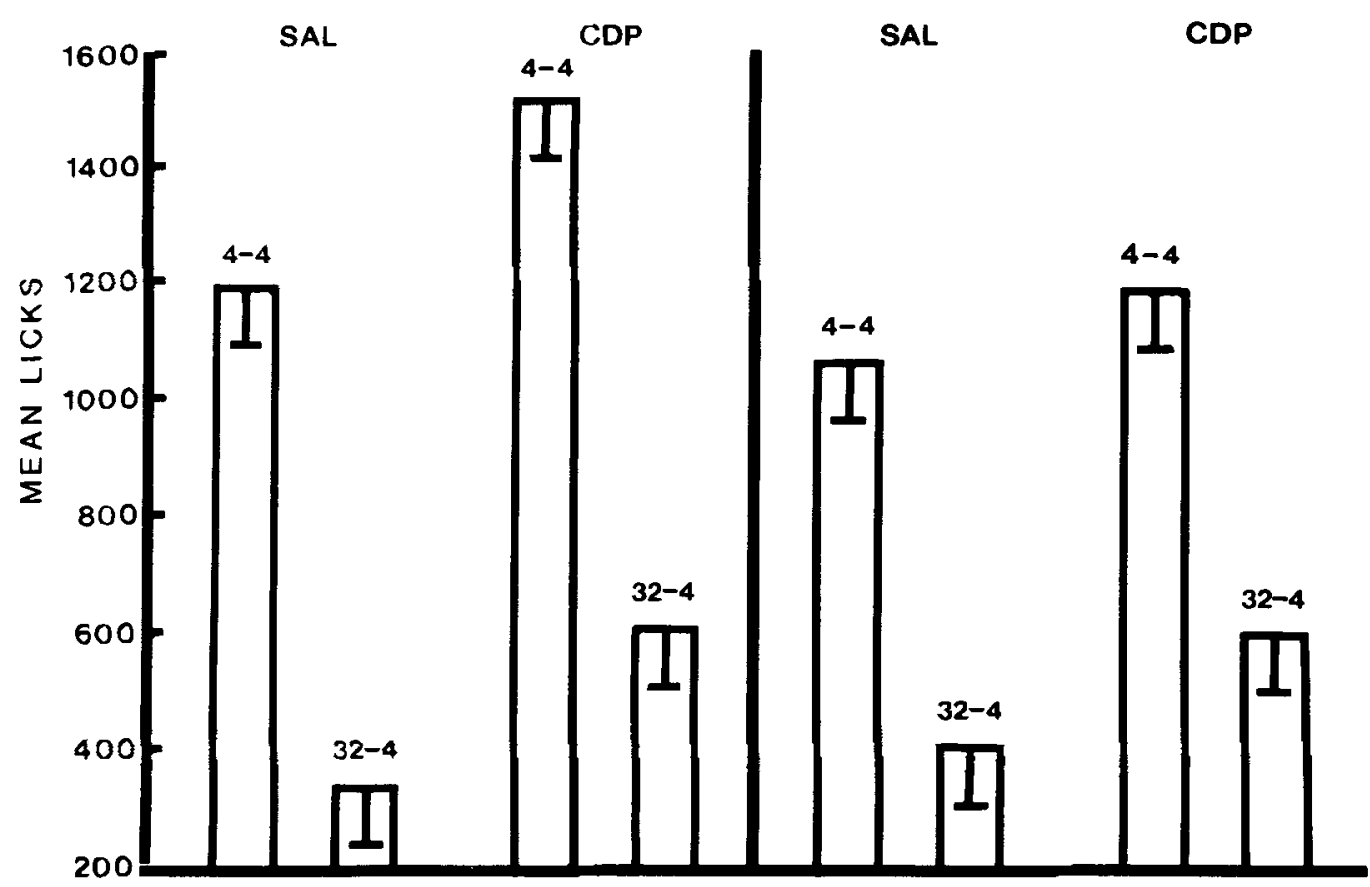

Figure 2. Mean lick frequency on first postshif day as a function of drug condition and hours since last preshift day. Chlordiazepoxide (CDP) did not reduce contrast. 
(e.g., Cooper \& Estall, 1985). Thus, the failure of CDP to affect contrast in this experiment cannot be related to a general lack of effectiveness of the drug.

These results, combined with those from earlier experiments, suggest that the greater effectiveness of CDP in reducing contrast on the second postshift day than on the first postshift day cannot be due to the second postshift day's being less stressful than the first postshift day (indeed, the corticosterone results suggest the opposite), nor can it be due to the passage of a 48-h interval since the last experience with the preshift reward. In Experiment $2 a$, we examined the possibility that the animals must have some experience with the postshift solution before the CDP becomes effective in reducing contrast.

\section{EXPERIMENT 2a}

In our experiments, the animals were given a 5-min access period to the sucrose solutions each day. This access time was selected originally because animals given access to $32 \%$ sucrose will begin to show signs of satiation with access periods slightly longer than $5 \mathrm{~min}$. However, this brief time period gives a somewhat arbitrary ring to the idea that a drug is effective on one postshift "day" but not on another "day." What makes the 5 -min access period of postshift Day 2 different from the 5 -min access period of Day 1 , if it is not the passage of time and it is not a reduced degree of stress? One thing that is clearly different about Day 2 is that the animals have already had a 5-min access period to the postshift solution. It is possible that some degree of experience with the postshift solution is necessary before CDP becomes effective in reducing contrast, and that other differences, such as time between Day 1 and Day 2, are not meaningful.

In this experiment, all 4 postshift days (5-min time periods) were given to the animals on the first day after the shift simply by allowing the animals access to the postshift solution for 20 continuous minutes. CDP was administered, as usual, 30 min prior to the start of the postshift period. If the Day 1-Day 2 difference in the effectiveness of CDP obtained in previous experiments was due to the animals' experience on the first postshift day, and not to the passage of time between preshift and postshift days, then the drug should begin to become effective in the second $5 \mathrm{~min}$ of the postshift period in the present experiment.

\section{Method}

Subjects. Twenty-four male Sprague-Dawley-derived rats about 90 days old were used as subjects. The animals were maintained as in Experiment 1.

Apparatus. The apparatus was the same as that used in Experiment 1

Procedure. During the preshift period, half of the animals (shifted group) were given access to a $32 \%$ sucrose solution for 10 days ( 5 min per day, timed from the first lick) and half of the animals were given access to a $4 \%$ sucrose solution. On the 11 th day, all animals were given access to the $4 \%$ sucrose solution for $20 \mathrm{~min}$, timed from the first lick. During this postshift period, half of the animals in each shift condition were injected with CDP $(8 \mathrm{mg} / \mathrm{kg})$ and half with isotonic saline. The injections were administered ip $30 \mathrm{~min}$ prior to the start of the session. The sucrose solutions were mixed as in Experiment 1

\section{Results}

Terminal preshift lick data indicated that the groups receiving $32 \%$ sucrose licked at a higher frequency (mean $=1,371$ ) than the group receiving $4 \%$ sucrose (mean $=$ $1,014)$. This difference was statistically reliable $[F(1,18)$ $=20.70, p<.001]$.

The data of interest in this experiment were the lick frequencies obtained over the first $10 \mathrm{~min}$ of the postshift period. These data are presented in Figure 3 in terms of the first and second 5-min periods (access periods corresponding to the usual first and second postshift days). During the first 5-min period, contrast was reliable in both the saline and CDP animals $[F(1,18)=30.88, p<.001]$, and CDP did not have a reliable overall effect on the animals' licking behavior $(F<1.00)$, nor did it reliably reduce contrast in the shifted animals [shift $\times$ drug $F(1,18)=2.14, p>.16]$. However, during the second 5 -min period there was no longer a contrast effect in the CDP animals, whereas the contrast was maintained in the saline animals [shift $\times$ drug $F(1,18)=6.38, p<.03$, followed by least significant difference tests, $p<.05$ ].

Thus, CDP became effective in reducing contrast during the second 5-min period (an access period coresponding to postshift Day 2) and was without effect during the first 5-min period (corresponding to postshift Day 1). The contrast-reducing effects of CDP came about primarily because the shifted CDP animals did not show a decline in lick frequency from the first 5-min period to the second 5-min period, whereas all other groups did show a decline in licking. These declines were reliable in both $4 \%$ control groups $[t(4)=21.36, p<.01$; and $t(5)=$ $8.37, p<.05$, for the saline and CDP groups, respectively]. The decline in the shifted saline group was not reliable $[t(4)=2.59, p>.05]$, and the shifted CDP group actually showed a slight numerical increase in licking in the second 5-min access period. Thus, the principal reason for the elimination of contrast in the CDP animals seems to be that the drug prevented a decline in lick frequency from the first to the second 5-min period, and it did so differentially in the shifted animals as compared to the unshifted controls.

A general decline in lick frequency occurred over the third and fourth 5-min access periods, and contrast was not reliable in either the saline or the CDP groups during this final $10 \mathrm{~min}$ of exposure (all $p \mathrm{~s}>.15$ ).

\section{Discussion}

CDP, although injected prior to the start of the postshift period, did not have reliable contrast-reducing effects until the second $5 \mathrm{~min}$ of the 20 -min postshift period. These results are consistent with those obtained in the stan- 


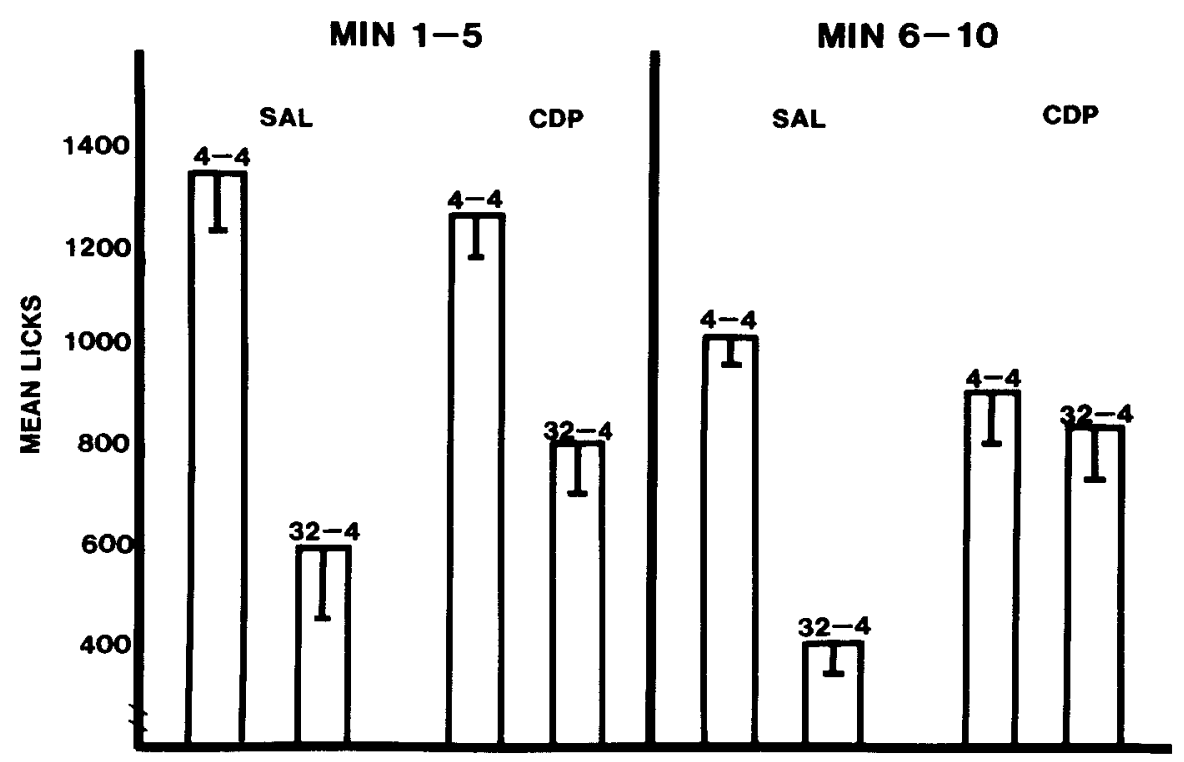

Figure 3. Mean lick frequency over first $5 \mathrm{~min}$ and second $5 \mathrm{~min}$ of the 20-min postshift period. Chlordiazepoxide (CDP) reduced contrast in the second 5 min.

dard contrast procedure, in which CDP is effective on the second postshift day but not on the first postshift day. The pattern of effectiveness suggests that some experience with the postshift solution is necessary before CDP becomes functional in reducing contrast. Since the correspondence between the results obtained in the standard procedure and those obtained in the 20-min postshift procedure used here was so remarkably close, we decided to run a replication before considering possible explanations for the temporal aspects of the CDP effects.

\section{EXPERIMENT 2b}

\section{Method}

Subjects. Twenty male Sprague-Dawley-derived rats served as subjects. The animals were maintained as in the previous experiments.

Apparatus. The apparatus was the same as that used in the previous experiments.

Procedure. The procedure was the same as that used in Experiment $2 \mathrm{a}$.

\section{Results}

One rat was dropped from the experiment for failure to lick the sucrose solution during the preshift period. Terminal preshift data showed that the rats given access to $32 \%$ sucrose licked more (mean $=1,533$ ) than the rats given access to $4 \%$ sucrose (mean $=1,154)$. This difference was statistically reliable $[F(1,16)=19.09$, $p<.01]$.

Data from the first $10 \mathrm{~min}$ of the postshift period are presented on a minute-by-minute basis in Figure 4. During the first 5-min period, the shifted animals licked substantially less than did the unshifted animals-a contrast effect that was reliable in both the saline animals $[F(1,8)$
$=6.30, p<.04]$ and the CDP animals $[F(1,7)=10.50$, $p<.02]$. The contrast effect was maintained in the second 5 -min period in the saline group $[F(1,8)=7.92$, $p<.03$ ], but there was no overall contrast effect in the CDP animals $[F(1,7)=1.84, p>.20]$. There was a reliable sucrose $\times$ minute interaction in the CDP group $[F(4,28)=2.76, p<.05]$, which indicated that a contrast effect was reliable in Minute 6 but not in Minutes 7-10, and that the rise in lick rate in the shifted CDP group from Minute 6 to Minute 7 was reliable (least significant difference tests, $p<.05$ ). Thus, as in Experiment $2 \mathrm{a}$, contrast was eliminated by CDP during the second $5 \mathrm{~min}$, but not during the first $5 \mathrm{~min}$, of the $20-\mathrm{min}$ access period.

During the last $10 \mathrm{~min}$ of the postshift period, there was no overall contrast effect $[F(1,15)=3.42, p>.05]$, nor was there a contrast $\times$ drug interaction $(F<1.00)$. CDP did continue to have a reliable effect in elevating lick frequency over this period in both shifted and unshifted animals $[F(1,15)=8.17, p<.05]$.

\section{Discussion}

The results of this experiment replicated those of Experiment $2 \mathrm{a}$ in showing that CDP was effective in reducing contrast during the second $5 \mathrm{~min}$ of the postshift period, but was ineffective during the first 5 min postshift. This experiment also showed that the drug became effective during the 7 th minute of the postshift period.

\section{GENERAL DISCUSSION}

Previous studies have shown that CDP reliably reduces contrast when it is administered for the first time on the second postshift day, but not when it is administered on 


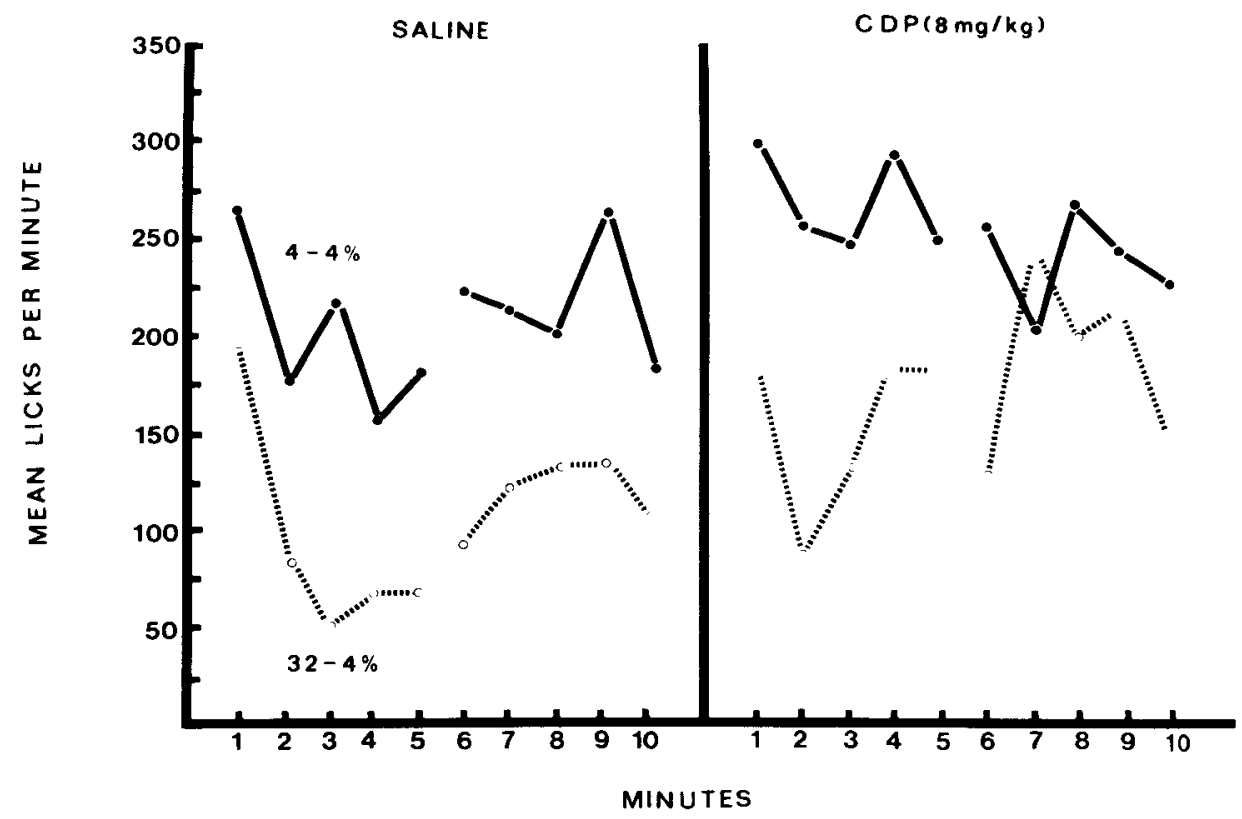

Figure 4. Mean minute-by-minute lick frequency over the first $10 \mathrm{~min}$ of the 20 -min postshift period. Chlordiazepoxide (CDP) reduced contrast in the second 5-min period, but not in the first 5-min period.

the first postshift day (Flaherty et al., 1980; Vogel \& Principi, 1971). Similar effects have been found with ethanol (Becker \& Flaherty, 1982).

A priori, one might think that the first postshift day would be more stressful than the second postshift day, and that, therefore, a reduced emotional response to the reward shift might be a reason why the drug becomes effective on the second postshift day. However, a previous study (Flaherty et al., 1985) showed that there is a substantial corticosterone elevation on the second postshift day, but none on the first postshift day. These results suggest that the second postshift day is more stressful than the first postshift day; therefore, the effectiveness of CDP on the second postshift day cannot be explained in terms of the drug's neutralizing a weaker emotional response.

In Experiment 1 we investigated another possible reason for temporal patterning in the effectiveness of CDPthe fact that on the second postshift day the animals are $48 \mathrm{~h}$ removed from their last experience with the preshift solution, whereas on the first postshift day they are only $24 \mathrm{~h}$ removed from this experience. This is potentially important, because the animals must compare the postshift solution with the memory of the preshift solution in order for a contrast effect to occur (Flaherty \& Lombardi, 1977; Spear, 1967). However, the results of Experiment 1 suggest that this differential retention interval is not an important factor. That is, contrast was not affected by CDP regardless of whether the first postshift day occurred $24 \mathrm{~h}$ or $48 \mathrm{~h}$ after the last preshift day. The lack of effectiveness of CDP on the first postshift day seems to be due to some characteristic of the first day per se.

In Experiments $2 a$ and $2 b$, the postshift phase was modified so that all $20 \mathrm{~min}$ of the postshift period, usually ad- ministered over 4 days, were experienced on the first postshift day. The results of both experiments suggest that CDP does not become effective in reducing contrast until the second $5 \mathrm{~min}$ of access to the postshift solution; the results of Experiment $2 b$ indicate that the effectiveness of the drug emerges around the 7th minute of access. Some degree of caution must be used in generalizing from these results to our standard contrast experiment: the procedures used in Experiments $2 \mathrm{a}$ and $2 \mathrm{~b}$ add the additional factor of satiation in the postshift period, something not noticeably present in the usual 5-min postshift periods. However, the comparable effectiveness of CDP obtained with the two procedures suggests that satiation over the first $10 \mathrm{~min}$ is probably not a major factor influencing the contrast-reducing properties of the drug.

The implication of the present results is that animals must have some degree of experience with the reduced level of reward before CDP becomes effective in moderating the degree of negative contrast. Furthermore, the previously mentioned corticosterone study (Flaherty et al., 1985) indicates that the experiential factor is not due to the postshift solution's becoming less aversive over the early stages of the postshift period; in fact, the opposite seems to be the case.

Why is some experience with the postshift solution necessary before CDP becomes effective in reducing contrast? One possibility is that contrast may be a dynamic process, with different mechanisms waxing and waning across the postshift period. Thus, contrast may initially be related to a generalization decrement or neophobic response as the animal first detects a difference between the postshift solution and the memory of the preshift solution. Informal observations suggest that the first major 
pause in licking by shifted animals occurs after about $20 \mathrm{sec}$ of access to the postshift solution. The animal's comparison of the postshift solution with the memory of the preshift solution may then lead to an evaluation process, the result of which is that the hedonic value of the postshift solution is found to be less than that of the memory of the preshift solution. As a result of this evaluation, the animal may be in a conflict situation-drawn to the $4 \%$ solution because of its absolute rewarding properties, but also repelled by this solution because it is relatively less rewarding than the $32 \%$ preshift solution. It may be that the animal is particularly stressed during this stage of conflict and that it is during this stage that CDP has an influence on reducing contrast by reducing the relative aversiveness of the postshift solution. The present experiments suggest that approximately a 5-min period of experience with the postshift solution is required before the reward downshift becomes aversive and before CDP becomes effective in moderating contrast.

This explanation seems complex, but the basic idea of a stage of conflict that develops with experience is similar to Amsel's hypothesis regarding the partial reinforcement extinction effect (Amsel, 1958, 1962), and the idea of sequential psychological processes that follow a reward loss is similar to Klinger's (1975) suggestion regarding the development of depression in humans. This analysis also suggests that the negative contrast procedure may involve mechanisms in the rat that could be analogous to disappointment in humans-a reward expectancy, the failure of that expectancy to be confirmed, a stress response, and the apparent relief of that stress by anxiolytics.

\section{REFERENCES}

AMSEL, A. (1958). The role of frustrative non-reward in noncontinuous reward situations. Psychological Bulletin, 55, 102-119.

AMSEL, A. (1962). Frustrative nonreward in partial reinforcement and discrimination learning. Psychological Review, 69, 306-328.

Amsel, A., Stanton, M. (1980). Ontogeny and phylogeny of paradoxical reward effects. In J. S. Rosenblatt, R. A. Hinde, C. Beer, \& M. C. Busnel (Eds.), Advances in the study of animal behavior. New York: Academic Press.

BeCKer, H. (1986). Comparison of the effects of the benzodiazepine midazolam and three serotonin antagonists on a consummatory conflict paradigm. Pharmacology, Biochemistry \& Behavior, 24, 1057-1064.

Becker, H. \& Flaherty, C. F. (1982). Influence of ethanol on contrast in consummatory behavior. Psychopharmacology, 77, 253-258.

BeCker, H., \& FlaherTy, C. F. (1983). Chlordiazepoxide and ethanol additivity reduce gustatory negative contrast. Psychopharmacology, 80, 35-37.

Ciszewski, W. A., \& Flaherty, C. F. (1977). Failure of a reinstatement treatment to influence negative contrast. American Journal of Psychology, 90, 219-229.
CoOper, S., \& Estall, L. (1985). Behavioral pharmacology of food and water and salt intake in relation to drug actions at benzodiazepine receptors. Neuroscience \& Biobehavioral Reviews, 9, 5-9.

Crespi, L. P. (1944). Amount of reinforcement and level of performance. Psychological Review, 51, 341-357.

Flaherty, C. F. (1982). Incentive contrast: A review of behavioral changes following shifts in reward. Animal Learning \& Behavior, 10, 409-440.

Flaherty, C. F., Becker, H., \& Driscoll, C. D. (1982). Conditions under which amobarbital sodium influences contrast in consummatory behavior. Physiological Psychology, 10, 122-128.

Flaherty, C. F., Becker, H. C., \& Pohorecky, L. (1985). Correlation of corticosterone elevation and negative contrast varies as a function of postshift day. Animal Learning \& Behavior, 13, 309-314.

FlaherTy, C. F., \& DRISCOLL, C. (1980). Amobarbital sodium reduces successive gustatory contrast. Psychopharmacology, 69, 161-162.

FlaherTy, C. F., \& LombaRDi, B. R. (1977). Effect of prior differential taste experience on retention of taste quality. Bulletin of the Psychonomic Society, 9, 391-394.

Flaherty, C. F., Lombardi, B. R., Wrightson, J., \& Deptula, D (1980). Conditions under which chlordiazepoxide influences successive gustatory contrast. Psychopharmacology, 67, 269-277.

Flaherty, C. F., \& Meinrath, A. B. (1979). Influences of scopolamine on sucrose intake under absolute and relative test conditions. Physiological Psychology, 1, 412-418.

Flaherty, C. F., \& Rowan, G. A. (1986). Successive, simultaneous, and anticipatory contrast in the consumption of saccharin solutions. Manuscript subrnitted for publication.

Gleitman, H. , \& Steinman, F. (1964). Depression effect as a function of retention interval before and after shift in reward magnitude. Journal of Comparative \& Physiological Psychology, 57, 158-160.

Gonzalez, R. C., Fernhoff, D., \& David, F. G. (1973). Contrast, resistance to extinction, and forgetting in rats. Journal of Comparative \& Physiological Psychology, 84, 562-571.

KLINGER, E. (1975). Consequences of commitment to and disengagement from incentives. Psychological Review, 82, 1-25.

Lombard, B. R., \& Flaherty, C. F. (1978). Apparent disinhibition of successive but not of simultaneous negative contrast. Animal Learning \& Behavior, 6, 30-42.

Rogerts, W. A., \& PIXley, L. (1965). The effect of chlorpromazine on the depression effect. Psychonomic Science, 3, 407-408.

Rosen, A. J., Glass, D. H., \& Ison, J. R. (1970). Amobarbital sodium and instrumental performance changes following reward reduction. Psychonomic Science, 9, 129-130.

Rosen, A. J. , Tessel, R. E. (1967). Chlordiazepoxide and incentive shift performance in the rat. Journal of Comparative \& Physiological Psychology, 72, 257-262.

Rowan, G. A., \& Flaherty, C. F. (1986). The effects of morphine on successive negative contrast. Manuscript submitted for publication.

SPEAR, N. E. (1967). Retention of reinforcer magnitude. Psychological Review, 74, 216-234.

SPENCE, K. W. (1956). Behavior theory and conditioning. New Haven, CT: Yale University Press.

Stanton, M., Lobough, N., \& Amsel, A. (1984). Age of first appearance of simultaneous and successive negative contrast in infant rats. Joumal of Experimental Psychology: Animal Behavior Processes, 10, 376-389.

VoGel, J. R., \& PRINCIPI, K. (1971). Effects of chlordiazepoxide on depressed performance after reward reduction. Psychopharmacologia, 21, 8-12.

(Manuscript received December 9, 1985; revision accepted for publication April 9, 1986.) 